DOI: $10.17805 / z p u .2016 .4 .15$

\title{
Образовательные практики в концептуальном поле социологии
}

\author{
А. Н. Пинчук \\ (МОСКОВСКИЙ ГУМАНИТАРНЫЙ УНИВЕРСИТЕТ)
}

В статье анализируется феномен образовательных практик в современном образовательном пространстве. Образовательные практики рассматриваются в контексте модернизации российской системы образования. Особое внимание при этом уделяется информатизации образовательного процесса, которая способствует формированию новых видов образовательных практик.

Анализ проблемы образовательных практик осуществляется сквозь призму социологии повседневности и социологии образования, которые позволяют более детально изучить особенности феномена образовательных практик. 
Образовательные практики трактуются как совокупность опривыченных действий, навыков, сконструированных в условиях приобретения и усвоения определенных знаний, включающих в себя также типизированные способы поиска и отбора новой информации с помощью различных средств и ресурсов и типизированные способы взаимодействия с другими участниками учебного процесса. Образовательные практики отражают некие привычки учиться определенным образом, сформированные в ситуации решения познавательно-исследовательских задач. Они актуализируются в процессе интенсификации познавательного интереса и активности индивида. В рамках данного подхода появляется возможность зафиксировать и изучить спектр образовательных практик, распространенных в современном образовательном пространстве, с указанием особенностей их объективных и субъективных параметров.

Ключевые слова: социальные практики; образовательные практики; формальное образование; неформальное образование; информальное образование; повседневная жизнь; рутинизация; российская система образования

\section{ВВЕАЕНИЕ}

$\mathbf{R}$ о второй половине $\mathrm{XX}$ в. в социологической теории активную разработку получила проблематика социальных практик, открывшая многоплановость и значимость мира повседневности. Текущая рутина жизненного потока перестала играть роль привычного фона, в силу своей обыденности не всегда воспринимаемого как самостоятельный феномен. Эвристический потенциал теории социальных практик позволил совершить мощный рывок в изучении ранее не исследованных механизмов функционирования общественных институтов и социального взаимодействия людей. В социологическом сообществе заговорили о «прагматическом повороте» в социально-гуманитарном знании, более того - о формировании практической парадигмы в социальных науках и о новых возможностях ее теоретико-методологического инструментария (Волков, 1997).

В целом использование концепта социальных практик прочно закрепилось в российской научно-исследовательской традиции, и уже сегодня накоплен богатый материал в области изучения различных явлений повседневности. Так, свое социологическое осмысление получили интернет-практики (Радкевич, 2009), практики чтения (Селиверстова, Юмашева, 2009), досуговые практики (Бутонова, 2012) и т. А. Однако до сих пор существуют определенные разновидности социальных практик, которые реже привлекают внимание ученых, но при этом их институционально значимая роль в воспроизводстве социальных структур бесспорна. В данном случае обращает на себя внимание сфера образования, которая всегда занимала важное место в жизни каждого индивида, становясь неотъемлемой частью его повседневного существования, формируя некую рутину образовательного процесса, входя в состав ежедневных практик, что как раз и представляет предмет изучения для социологии повседневности и социологии образования. Тем самым выделяется особый социальный феномен образовательных практик, интерес к которому становится более очевидным, если подчеркнуть факт непрерывного образования как данность современных социальноэкономических условий. Ведь сегодня учебная деятельность стала сопровождать человека на протяжении всей его жизни, и, естественно, осуществляется она через закрепленные способы получения и усвоения новых знаний, умений, навыков, с одной стороны, и посредством привычки учиться определенным образом - с другой. Именно этот аспект процесса обучения как раз и отражают образовательные практики. Выделение этой разновидности практик в качестве самостоятельного феномена требует его концептуализации сквозь призму социологических теорий, что в дальнейшем позволит проработать данную тематику и на методологическом уровне. 
ОПРЕАЕАЕНИЕ ТЕРМИНА «ОБРАЗОВАТЕАЬНЫЕ ПРАКТИКИ»

Непосредственно о «практиках» как об особом социальном явлении, который возможно и нужно изучать, заговорили в 1970-е годы в связи с публикацией работы П. Бурдье «Практический смысл» (Бурдье, 2001). С тех пор в социологии развилось целое направление, посвященное теме социальных практик, что, безусловно, способствовало более глубокому пониманию затрагиваемого феномена. Но это также привело к тому, что разноплановые трактовки введенной в научный оборот дефиниции «социальные практики» затруднили ее однозначную смысловую коннотацию (Иванова, 2014; Аьяков, 2011: 208). Тем не менее можно выделить ряд общепризнанных концепций зарубежных и российских авторов, которые известны своими подходами в изучении повседневных практик. К ним принято относить теорию структурации Э. Гидденса, структуралистский конструктивизм П. Бурдье, этнометодологию Г. Гарфинкеля, феноменологию А. Щюца и др. В отечественной науке проблематика обыденного, рутинного существования и типизированных в их контексте действий обозначилась в научном дискурсе благодаря работам таких ученых, как В.В. Волков, О. В. Хархордин, Ю. М. Резник, А. А. Аьяков, Н. А. Селиверстова, Вал. А. Ауков, О. М. Божков, И. В. Глушко и ар.

В целом теория социальных практик имеет должное теоретико-методологическое обоснование, что позволяет концептуализировать их конкретные виды, а в нашем случае образовательные практики. Понятие «образовательные практики» преимущественно используется в педагогической литературе. Педагоги интерпретируют данное понятие как определенный опыт, практику преподавания, практику учебно-педагогического взаимодействия (Аебедев, 2009; Захаров, Фрумин, Кузьминов, 2011). В социологии понятие «образовательные практики» встречается в связи с исследованием субкультурных общностей (Власова, 2014) либо выделяются социальные практики в образовательной среде наряду с другими их разновидностями (Балич, 2013). Развернутое определение образовательным практикам дала Н. А. Селиверстова (Селиверстова (а), Электронный ресурс). Мы попытаемся обозначить содержательную специфику понятия «образовательные практики» более конкретно.

Образовательные практики представляют собой совокупность опривыченных действий, навыков, выработанных в условиях приобретения и усвоения определенных знаний, также включающих в себя типизированные способы поиска и отбора новой информации с помощью различных средств и ресурсов и типизированные способы взаимодействия с другими участниками учебного процесса. Иначе говоря, образовательные практики отражают некие привычки учиться определенным образом, сформированные в ситуации решения познавательно-исследовательских задач. Они актуализируются в процессе интенсификации познавательного интереса и активности. Обозначенный подход к определению феномена образовательных практик позволяет охватить спектр повседневных практик в расширенной образовательной среде, т. е. к ним относятся и практики, сформированные в процессе прохождения всех этапов формального, неформального образования, также в сфере самообразования, информального образования. Следует уточнить, что к неформальному образованию относятся все виды обучения, которые не входят в программы формального образования (например, курсы, тренинги, различные лекции, семинары и т. А.) (Шувалова, 2010). Самообразование, или информальное образование, включает «неформальное индивидуальное обучение, которое в отличие от формального образования и дополнительного образования осуществляется самостоятельно и не фиксируется в дипло- 
ме или ином документе, но вносит вклад в расширение знаний и умений» (там же: 179). По мнению Е. А. Смирновой, «феномен социальной практики отличает воспроизводимость, устойчивость, массовость и нормативность» (Смирнова, 2015: 45). Предполагается, что это характерно и для образовательных практик.

\section{ФЕНОМЕН ОБРАЗОВАТЕАЬНЫХ ПРАКТИК: \\ УСАОВИЯ ФОРМИРОВАНИЯ И ОСНОВНЫЕ ВИАЫ}

Одно из важнейших свойств социальных практик - их пространственно-временная локализация, что особо подчеркивал известный социолог Э. Гидденс (Гидденс, 2005: 174-235). Это делает необходимым изучение особенностей образовательного пространства, условий, в которых происходит воспроизводство образовательных практик. Здесь можно выделить как образовательные организации (в системе формального образования) с характерной для них социокультурной средой, внутренним распорядком, а также домашнюю обстановку и т. А. в качестве обстановки условий формирования типизированных способов обучения. Особое место в современном образовательном пространстве занимает формальное образование, поэтому обратимся в первую очередь к его системе как условиям формирования габитуса в образовательной среде. Отдельно отметим, что впервые термин «габитус» был введен П. Бурдье. Согласно его определению «габитусы - системы устойчивых и переносимых диспозиций, структурированные структуры, предрасположенные функционировать как структурирующие структуры, т. е. как принципы, порождающие и организующие практики и представления...» (Бурдье, 2001: 44). В этой связи рассмотрим российскую систему образования как условия формирования «структурирующих структур».

В современном обществе обучение начинается, как правило, в дошкольных организациях, которое с 2013 г. регламентируется Федеральным государственным образовательным стандартом (ФГОС) дошкольного образования (Федеральный государственный ..., 2013: Электронный ресурс). В рамках общеразвивающих программ при подготовке к школе дети совершенствуют речевые способности, получают базовое представление о природе, явлениях, происходящих в ней, основах жизни общества, овладевают навыками счета и чтения и т. д. То есть уже при первоначальном обучении отрабатываются определенные способы постижения новых знаний, закрепления усвоенной информации, ее запоминания и обобщения. Тем самым дошкольные организации выступают в качестве отправной точки при формировании габитуса в сфере формального образования, и первоначальное обучение в данном случае порождает предпосылки к конструированию определенных практик.

Следующим значительным этапом в прохождении ступеней формального образования является школьный период, который, несомненно, важен в жизни каждого человека и играет существенную роль в процессе интенсивного личностного становления. Повседневная школьная жизнь протекает согласно плану с заранее фиксированным распорядком дня, заполненным уроками, разнообразными формами внеурочной и внеклассной работы, спортивными, творческими и другими организационно-воспитательными мероприятиями. Взаимодействие между субъектами учебного процесса также регламентировано определенными нормами и правилами образовательной организации. Общение между учениками и преподавателями, межгрупповая коммуникация происходят в контексте как формальных, так и неформальных статусно-ролевых позиций, что указывает на формирование различных траекторий социальной интеракции. Происходит как некая типизация социальных действий, связанных с обу- 
чением, так и типизация социальных взаимоотношений между учениками и учителем, одноклассниками или группами учеников и т. А. (Селиверстова, 2015; Селиверстова (b): Электронный ресурс). Ежедневные практики посещения уроков и подготовки домашних заданий, поиска и освоения материала, практики демонстрации усвоенных знаний характеризуют сложившийся опривыченный способ обучения индивидов в рамках выполнения учебного плана. Понимание того, как привыкли учиться школьники, особенно актуально сегодня, когда вместе с традиционными техниками проведения уроков активно используются и современные педагогические технологии (организационно-деятельностные, деловые игры, методы проектов, проблемное обучение и др.), реализация которых создает условия для формирования новых способов заучивания и усваивания учебного материала.

Свою специфику образовательные практики приобретают и при дальнейшем обучении в организациях среднего профессионального или высшего образования. Следует заметить, что некоторые привычки учиться будут воспроизводиться в течение всей жизни акторов, например, те, которые были приобретены еще в школе. При этом в ходе дальнейшего обучения происходит формирование особых видов образовательных практик, характерных для социокультурной среды определенной образовательной организации, например колледжа, института, университета. В этой связи особое внимание следует обратить на получение профессионального образования в высших учебных заведениях, где педагогическая деятельность осуществляется с применением специальных педагогических технологий высшей школы в рамках реализации компетентностной парадигмы. Как правило, уже с первого курса молодые люди вырабатывают определенные образовательные практики, связанные с необходимостью усваивания большого массива информации на лекционных занятиях, во время подготовки к семинарам в форме докладов, рефератов, презентаций и осуществления иной научно-исследовательской работы. Практики сдачи экзаменов и зачетов представляют отдельную тему, которая нередко становится предметом иронии по поводу «изобретательности» студентов. Здесь можно выделить как легитимные, так и нелегитимные виды образовательных практик. Ярким примером может служить написание курсовой работы. Студенты могут писать курсовые самостоятельно, собирать необходимый материал, читать статьи и монографии, что в принципе представляет собой одобряемую практику. Но есть и другие формы поведения, когда учащиеся не готовят сами, а предпочитают заказывать чужие работы за определенную плату, скачивают из Интернета готовые материалы и т. д. Аанные методы, конечно, скрываются из-за риска применения возможных санкций, что необходимо учитывать при исследовании на эмпирическом уровне.

Влияние и включенность современных средств связи и техники в учебный процесс молодого поколения изучается современными социологами (Королева, 2016). Сегодня роль новых информационных технологий в жизни социума как в целом, так и в отдельных его областях, безусловно, велика. Современное «общество знания», общество непрерывного образования невозможно представить без огромного потока информации с моментальной скоростью ее передачи на большие расстояния. Все это, конечно, упрощает процесс получения и поиска необходимых сведений, и интернетресурсы заняли место приоритетного источника данных. Не углубляясь в рассмотрение проблемных зон, порожденных интернет-коммуникациями, отметим, что качество многих учебных сайтов на данный момент сомнительно, а отсюда возникает вопрос и о качестве материала (готовые рефераты, непроверенные статьи), на основе кото- 
рых привыкли готовиться студенты к семинарам, зачетам, экзаменам (Селиверстова, 2011). Тот факт, что большинство учащихся используют электронные ресурсы взамен библиотечных фондов, подтверждается последними исследованиями социологов (см.: Королева, 2016; Селиверстова, 2011), и здесь скорее уместно говорить об определенных интернет-практиках как разновидности образовательных практик: какие сайты больше всего востребованы у студентов, используют ли один источник или компонуют несколько, что больше задействовано - печатные учебники или электронные, какие электронные ресурсы предпочитают студенты (базы данных рефератов либо научные журналы и т. д.). На данный момент уже можно найти ответы на часть поставленных вопросов.

Социальные практики чтения контента Интернета студентами российских вузов изучались Н. А. Селиверстовой. Показательны результаты проведенного автором исследования в 2011 г. в Московском гуманитарном университете. Анализируя способы подготовки студентов к занятиям, Н. А. Селиверстова пишет: «...абсолютное большинство студентов находили материал по конкретному вопросу, скачивали, распечатывали, выделяли главные моменты и подчеркивали их, чтобы затем зачитать на семинаре. Аанная распространенная студенческая практика ведет к тому, что выпадают такие стратегии чтения в образовательном процессе, как запись информации своими словами, т. е. парафраз и суммирование информации в виде информационного текста. Из цикла выпадают важнейшие стратегии» (Селиверстова, 2011: 216).

В этой связи уместно затронуть и проблему практики чтения в целом, которая неразрывно связана с образовательными технологиями. Проблема сегодня особенно актуальна в условиях общего снижения уровня потребления книжной продукции. Аля обучающейся молодежи чтение как досуговое, так и в целях образования должно находиться в разделе ежедневных практик, но, как показывают последние исследования, эти практики заменяются новыми - «практиками сидения в Интернете» (Селиверстова, Юмашева, 2009: 95).

Учеба осуществляется и в системе неформального образования, посредством самообразования, информального образования, о чем уже говорилось. Выделение образовательных практик, наполняющих повседневную жизнь в школах, колледжах, университетах, позволяет охватить широкий спектр их разнообразных видов. Однако более детальное изучение затрагиваемого феномена требует проанализировать возможные виды образовательных практик и в сфере неформального образования, самообразования, информального образования. Так, постоянное взаимодействие и общение с разными людьми, посещение выставок, концертов и других культурных мероприятий, чтение книг, самообразование и т. А. играют огромную роль в образовательном процессе индивида и тоже включают набор определенных практик получения новых знаний и навыков. И если некоторые моменты выделить в информальном образовании методологически сложно и спорно, то в системе неформального образования это все-таки сделать можно.

В отличие от формального неформальное образование не требует жесткой регламентации. В научной литературе неформальное образование тесно связано с процессом «непрерывного образования», с реалиями «общества знания», призванного обеспечить равный доступ к реализации личностного потенциала в течение всей жизни (Бирюкова, 2012). Аействительно, на сегодняшний день широко распространены различные курсы обучения иностранному языку, бизнес-тренинги, общественные семинары, мастер-классы, лекции и т. А. В зависимости от интереса и нацеленности совре- 
менные люди в любом возрасте могут начать учиться живописи или актерскому мастерству. Посещение этих курсов может идти как параллельно учебе в школе, колледже, вузе, так и спустя определенное время в качестве досуга либо профессионального совершенствования. Как правило, методики обучения в таких местах отличаются доступностью передачи материала небольшого объема с привлечением деятельностного подхода. Скорее всего, обучающиеся в данной ситуации будут тратить минимальное время на усвоение новой информации. Отсюда можно предположить, что и объем материала, и уровень отработанного мастерства будет лимитирован тем, что успели усвоить индивиды непосредственно на проводимом курсе. Здесь нет необходимости подтверждать свой уровень знаний, и спектр образовательных практик скорее всего не сильно будет отличаться от усвоенных ранее, но это не исключает наличие специфики практик именно в неформальном образовании.

Вышеперечисленные виды образовательных практик репрезентируют некую картину текущей повседневности, объективно наблюдаемую сторону социальной реальности.

Изучать и фиксировать социальные практики сложно, но реально. Здесь важно учитывать как их объективные, так и субъективные составляющие. Вопрос о внутреннем содержании, субъективном основании социальных практик требует отдельного обсуждения. В первую очередь интересует момент осознания, рефлексивности в структуре рутинизированных по своей сути действий. Говорить о постоянном осознанном мониторинге и рефлексии актора в данном случае будет не совсем верно. Г. Гарфинкель писал: «...процедура принятия решений до реальной ситуации выбора условий, при которых будет выбрана одна из совокупности последовательных действий, - это дефиниция рациональной стратегии. Следует отметить, что данное рациональное свойство процесса принятия решений в повседневной жизни совершенно отсутствует» (Гарфинкель, 2007: 124-125).

П. Бурдье в свою очередь указывал на практическое чувство и логику агента. Они предполагают не прямое осмысление действия, а некое неведение, имеются в виду функционирующие имплицитно схемы, которые содержат смысл, но прямо не осознаются. «Наиболее хитрая ловушка состоит здесь в том, что агенты охотно прибегают к двусмысленному языку правил (грамматическому, моральному или юридическому), дабы объяснить социальную практику, подчиняющуюся совсем иным принципам, и тем самым скрывают от самих себя, в чем истинная суть их практического умения это ученое неведение, т. е. особый способ практического знания, не включающего в себя знание своих принципов», - пишет Бурдье (Бурдье, 2001: 89).

Э. Гидденс выстраивает логику анализа, согласно которой он различает понятия рефлексивного мониторинга, рационализации действия и его мотивации: «Если причины относятся к основаниям тех или иных действий, то мотивы следует считать желаниями или потребностями, побуждающими совершать их. Вместе с тем в отличие от рефлексивного мониторинга и рационализации мотивация не связана напрямую со связностью и последовательностью действий. Мотивы имеют прямое отношение к действию только в относительно необычных или нестандартных условиях, в ситуациях, которые некоторым образом нарушают привычный (рутинный) ход событий... подсознательная мотивация есть существенная особенность и характерная черта человеческого поведения...» (Гидденс, 2005: 45).

То есть прямая мотивация не характерна для повседневных действий. Однако социальные практики имеют смыслы, при этом включены они в телесность и ограниче- 
ны отчасти бессознательным. На это указывает А. Н. Иванова: «Субъектным основанием социальных практик является телесность, которая в процессе седиментации наполняется различного рода императивами (смысловыми и поведенческими)» (Иванова, 2014: 81). 3десь правильнее говорить не столько о непосредственном рациональном и сознательном, сколько «о бинарном и амбивалентном характере субъективного основания социальных практик» (там же).

Эти особенности значительно усложняют изучение практик, но их необходимо учитывать, так как они отражают сущностный аспект данного феномена. То, что «знание о практиках - это знание не объективируемое», замечали В. В. Волков и О. В. Хархордин (Волков, Хархордин, 2008: 42). При этом сами авторы указывают: «Практики конституируют и воспроизводят идентичности или “раскрывают" основные способы социального существования, возможные в данной культуре и в данный момент истории... Тогда общество можно представить как множество раскрывающих разнообразные смыслы пространств, характеризующихся инструментальным снаряжением, совокупностью навыков, практическими проектами и идентичностями» (Волков, 1997: 16). Это положение успешно используется некоторыми авторами в качестве методологической базы при исследовании социальных практик. Например, М. Ю. Гудова при изучении практик чтения, основываясь на концепции П. Бурдье, методике анализа В. В. Волкова и О. В. Хархордина, обозначает такие параметры сравнения различных культурных практик чтения, как снаряжение, операциональные навыки, ценности и идентичности (Гудова, 2014: 84).

Таким образом, некоторые субъективные аспекты в социальных практиках выделить и эксплицировать сложно, методологически спорно, но представляется возможным рассмотреть ценностный компонент, социальную установку и идентичность обучающихся в качестве субъективных показателей.

\section{ЗАКАЮЧЕНИЕ}

Образовательные практики часто остаются за рамками традиционных исследовательских интересов, рутина образовательного процесса - это опять-таки незамеченный фон. Развитие концепта социальных практик показало, что иногда достаточно поменять ракурс обзора, и ранее привычные вещи видятся с новой стороны, открывая свою значимость. Возможно, и при изучении образовательной реальности следует совершить некий «прагматический поворот», в чем поможет разработка теории образовательных практик.

Сегодня образовательные практики часто остаются за рамками традиционных исследовательских интересов, однако представляют важную разновидность повседневных практик в обществе непрерывного образования. В условиях, когда необходимо заниматься своим образованием в течение всей жизни, важно понимание того, как привыкли учиться современные индивиды, какие инструменты и ресурсы обычно используют, как протекает их рутина учебного процесса. Это следует учитывать и в педагогической деятельности, и в построении принципов организации процесса обучения в формальной системе образования в целях поиска наиболее эффективных и адекватных путей ее модернизации.

\section{СПИСОК АИТЕРАТУРЫ}

Балич Н. А. (2013) Социальные практики и их роль в современном обществе // Социология: теория, методы, маркетинг. № 4. С. 69-78. 
Бирюкова, И. К. (2012) Неформальное образование: понятие и сущность // Известия Волгоградск. гос. пед. ун-та. № 10. Т. 74. С. 18-20.

Бурдье, П. (2001) Практический смысл : пер. с фр. СПб. : Алетейя ; М. : Ин-т эксперимент. социологии. 562 с.

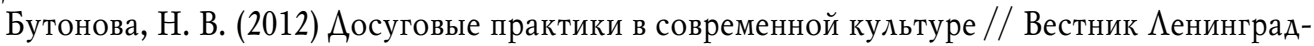
ского государственного университета им. А. С. Пушкина. Т. 2. № 1. С. 201-210.

Власова, О. В. (2014) Молодежные субкультурные общности: образовательные практики в условиях северного города : автореф. дис. ... канд. социол. наук. Екатеринбург. 26 с.

Волков, В. В. (1997) О концепции практик(и) в социальных науках // Социологические исследования. №6. С. 9-23.

Волков, В. В., Хархордин, О. В. (2008) Теория практик. СПб. : Изд-во Европейского университета в Санкт-Петербурге. 297 с.

Гарфинкель, Г. (2007) Исследования по этнометодологии : пер. с англ. СПб. : Питер. 335 с.

Гидденс, Э. (2005) Устроение общества. Очерк теории структурации. 2-е изд. М. : Академический Проект. 528 с.

Гудова, М. Ю. (2014) Чтение как культурная практика: обоснование методологии исследования // Вестн. Челябинск. Гос. академии культуры и искусств. № 3 (39). С. 82-88.

Аьяков, А. А. (2011) Практики как предмет социально-философского дискурса // Вестн. Поволж. ин-та управления. №3. С. 208-213.

Захаров, А. Б., Фрумин, И. А., Кузьминов, Я. И. (2011) Российская школа: альтернатива модернизации сверху // Вопросы образования. № 3. С. 5-53.

Иванова, Н. А. (2014) Социальные практики: условие возможности, сущность и многообразие форм // Вестн. Челябинск. гос. ун-та. № 17. С. 76-82.

Королева А. О. (2016) Всегда онлайн: использование мобильных технологий и социальных сетей современными подростками дома и в школе // Вопросы образования. №1. С. 205-224. DOI: $10.17323 / 1814-9545-2016-1-205-224$

Иебедев, О. Е. (2009) Результаты школьного образования в 2020 г. // Вопросы образования. № 1. C. 40-59.

Радкевич, А. $\Lambda$. (2009) Интернет-аудитория в России: состояние, динамика, тенденции // Знание. Понимание. Умение. № 1. С. 230-236.

Селиверстова, Н. А. (2011) Социальные практики чтения контента Интернета в студенческой среде // Знание. Понимание. Умение. № 1. С. 213-217.

Селиверстова, Н. А. (2015) Образовательный опыт как понятие социологии // Знание. Понимание. Умение. № 2. С. 79-87. DOI: 10.17805/zpu.2015.2.8

Селиверстова, Н. А. (а) Образовательные практики [Электронный ресурс] // Социология молодежи. Электронная энциклопедия. URL: http://www.soc-mol.ru/encyclopaedia/youth/278obrazovatelnye-praktiki.html (дата обращения: 10.09.2016).

Селиверстова, Н. А. (b) Образовательный опыт молодежи [Электронный ресурс]// Социология молодежи. Электронная энциклопедия. URL: http://www.soc-mol.ru/encyclopaedia/ youth/19-obrazovatelnyy-opyt-molodezhi.html (дата обращения: 10.09.2016).

Селиверстова, Н. А., Юмашева, Н. А. (2009) Чтение в студенческой среде: опыт социологического исследования. М. : Российская книжная палата. 108 с.

Смирнова, Е. А. (2015) Теоретико-концептуальные подходы к изучению феномена социальной практики // Экология человека. № 1. С. 40-48.

Федеральный государственный образовательный стандарт дошкольного образования (утв. приказом Министерства образования и науки РФ от 17 октября 2013 г. № 1155) [Электронный ресурс] // Информационно-правовой портал ГАРАНТ.PУ. URL: base.garant.ru/70512244 (дата обращения: 08.09.2016).

Шувалова, О. Р. (2010) Международные индикаторы участия населения в непрерывном образовании // Вопросы образования. №2. С. 178-186. 


\section{EDUCATIONAL PRACTICE AS A SOCIOLOGICAL CONCEPT \\ A. N. PINCHUK \\ (MOSCOW UNIVERSITY FOR THE HUMANITIES)}

The article problematizes the phenomenon of educational practices in contemporary educational space, within the context of modernization of the Russian education system. Special attention should be paid to introducing information technologies into the educational process, thus promoting the rise of new practices in education. The author examines the educational practices through the prism of sociology of everyday life and sociology of education.

Educational practices can be defined as a set of customary actions and skills, constructed in the course of acquiring and mastering specific knowledge. This knowledge also includes streamlined methods of searching for and selecting new information using a variety of tools and resources, as well as streamlined modes of interaction with other participants of the educational process. Educational practices reflect certain learning habits which have been formed while solving specific educational problems. They can be actualized in the course of intensification of cognitive interest and individual activity. This approach makes it possible to outline and examine the whole spectrum of educational practices prevalent in contemporary educational space, as well as the full characteristics of their objective and subjective parameters.

Keywords: social practices; educational practices; formal education; non-formal education; informal education; everyday life; routinization; educational system in Russia

\section{REFERENCES}

Balich N. L. (2013) Sotsial'nye praktiki i ikh rol' v sovremennom obshchestve. Sotsiologiia: teoriia, metody, marketing, no. 4, pp. 69-78. (In Russ.)

Biriukova, I. K. (2012) Neformal'noe obrazovanie: poniatie i sushchnost'. Izvestiia Volgogradsk. gos. ped. un-ta, no. 10, vol. 74, pp. 18-20. (In Russ.)

Bourdieu, P. (2001) Prakticheskii smysl. St. Petersburg, Aleteiia; Moscow, In-t eksperiment. sotsiologii. 562 p. (In Russ.)

Butonova, N. V. (2012) Dosugovye praktiki v sovremennoi kul'ture. Vestnik Leningradskogo gosudarstvennogo universiteta im. A. S. Pushkina, vol. 2, no. 1, pp. 201-210. (In Russ.)

Vlasova, O. V. (2014) Molodezhnye subkul' turnye obshchnosti: obrazovatel' nye praktiki v usloviiakb severnogo goroda: Thesis of Diss. ... Candidate of Sociology. Ekaterinburg. 26 p. (In Russ.)

Volkov, V. V. (1997) O kontseptsii praktik(i) v sotsial'nykh naukakh. Sotsiologicheskie issledovaniia, no. 6, pp. 9-23. (In Russ.)

Volkov, V. V. and Kharkhordin, O. V. (2008) Teoriia praktik. St. Petersburg, Izd-vo Evropeiskogo universiteta v Sankt-Peterburge. 297 p. (In Russ.)

Garfinkel, G. (2007) Issledovaniia po etnometodologii. St. Petersburg, Piter. 335 p. (In Russ.)

Giddens, A. (2005) Ustroenie obshchestva. Ocherk teorii strukturatsii. 2e ed. Moscow, Akademicheskii Proekt. 528 p. (In Russ.)

Gudova, M. Yu. (2014) Chtenie kak kul'turnaia praktika: obosnovanie metodologii issledovaniia. Vestn. Cheliabinsk. Gos. akademii kul'tury i iskusstv, no. 3 (39), pp. 82-88. (In Russ.)

D'iakov, A. A. (2011) Praktiki kak predmet sotsial'no-filosofskogo diskursa. Vestn. Povolzh. in-ta upravleniia, no. 3, pp. 208-213. (In Russ.)

Zakharov, A. B., Frumin, I. D. and Kuz'minov, Ya. I. (2011) Rossiiskaia shkola: al'ternativa modernizatsii sverkhu. Voprosy obrazovaniia, no. 3, pp. 5-53. (In Russ.)

Ivanova, N. A. (2014) Sotsial'nye praktiki: uslovie vozmozhnosti, sushchnost' i mnogoobrazie form. Vestn. Cheliabinsk. gos. un-ta, no. 17, pp. 76-82. (In Russ.)

Koroleva D. O. (2016) Vsegda onlain: ispol'zovanie mobil'nykh tekhnologii i sotsial'nykh setei sovremennymi podrostkami doma i v shkole. Voprosy obrazovaniia, no. 1, pp. 205-224. DOI: 10.17323/1814-9545-2016-1-205-224 (In Russ.)

Lebedev, O. E. (2009) Rezul'taty shkol'nogo obrazovaniia v 2020 g. Voprosy obrazovaniia, no. 1, pp. 40-59. (In Russ.) 
Radkevich, A. L. (2009) Internet-auditoriia v Rossii: sostoianie, dinamika, tendentsii. Znanie. Ponimanie. Umenie, no. 1, pp. 230-236. (In Russ.)

Seliverstova, N. A. (2011) Sotsial'nye praktiki chteniia kontenta Interneta v studencheskoi srede. Znanie. Ponimanie. Umenie, no. 1, pp. 213-217. (In Russ.)

Seliverstova, N. A. (2015) Obrazovatel'nyi opyt kak poniatie sotsiologii. Znanie. Ponimanie. Umenie, no. 2, pp. 79-87. DOI: 10.17805/zpu.2015.2.8 (In Russ.)

Seliverstova, N. A. (a) Obrazovatel'nye praktiki. Sotsiologiia molodezhi. Elektronnaia entsiklopediia [online] Available at: http://www.soc-mol.ru/encyclopaedia/youth/278-obrazovatelnyepraktiki.html (access data: 10.09.2016). (In Russ.)

Seliverstova, N. A. (b) Obrazovatel'nyi opyt molodezhi. Sotsiologiia molodezhi. Elektronnaia entsiklopediia [online] Available at: http://www.soc-mol.ru/encyclopaedia/youth/19-obrazovatelnyy-opyt-molodezhi.html (access data: 10.09.2016). (In Russ.)

Seliverstova, N. A. and Iumasheva, N. D. (2009) Chtenie v studencheskoi srede: opyt sotsiologicheskogo issledovaniia. Moscow, Rossiiskaia knizhnaia palata. 108 p. (In Russ.)

Smirnova, E. A. (2015) Teoretiko-kontseptual'nye podkhody k izucheniiu fenomena sotsial'noi praktiki. Ekologiia cheloveka, no. 1, pp. 40-48. (In Russ.)

Federal'nyi gosudarstvennyi obrazovatel'nyi standart doshkol'nogo obrazovaniia (utv. prikazom Ministerstva obrazovaniia i nauki RF ot 17 oktiabria 2013 g. № 1155). Informatsionno-pravovoi portal GARANT.RU [online] Available at: base.garant.ru/70512244 (access data: 08.09.2016). (In Russ.)

Shuvalova, O. R. (2010) Mezhdunarodnye indikatory uchastiia naseleniia v nepreryvnom obrazovanii. Voprosy obrazovaniia, no. 2, pp. 178-186.

Submission date: 12.09 .2016$.

Пинчук Антонина Николаевна - аспирант кафедры социологии Московского гуманитарного университета. Адрес: 111395, Россия, г. Москва, ул. Юности, д. 5. Тел.: +7 (499) 374-60-21. Эл. адрес: antonina.pinchuk27@bk.ru. Научный руководитель - А-р социол. наук, проф. Н. А. Селиверстова.

Pinchuk Antonina Nikolaevna, Postgraduate student, Department of Sociology, Moscow University for the Humanities. Postal address: 5 Yunosti St., Moscow, Russian Federation 111395. Tel.: +7 (499) 374-60-21. E-mail: antonina.pinchuk27@bk.ru. Research advisor: Doctor of Sociology, Professor N. A. Seliverstova. 